\title{
Neuroleptic malignant syndrome in the acquired immunodeficiency syndrome
}

\author{
José L Hernández, Luis Palacios-Araus, Santiago Echevarría,
} Andrés Herrán, Juan F Campo, José A Riancho

\begin{abstract}
Summary
Patients infected by the human immunodeficiency virus are predisposed to many infectious and noninfectious complications and often receive a variety of drugs. Furthermore, they seem to have a particular susceptibility to idiosyncratic adverse drug reactions. It is therefore surprising that only a few cases of the neuroleptic malignant syndrome have been described in patients with the acquired immunodeficiency syndrome. A high index of suspicion is required to diagnose the neuroleptic malignant syndrome in these patients, as its usual manifestations, including fever and altered consciousness, are frequently attributed to an underlying infection.
\end{abstract}

Keywords: neuroleptic malignant syndrome, acquired immunodeficiency syndrome, antipsychotic agents
The neuroleptic malignant syndrome (NMS) is a life-threatening process, typically, but not exclusively, induced by drugs of the neuroleptic group. Its main clinical manifestations include fever, rigidity of skeletal muscles, fluctuating consciousness and autonomic disturbances. ${ }^{1}$ Since first described by Delay and Deniker in $1968,{ }^{2}$ the syndrome has received increasing attention and more than 1600 cases have been reported to date, including a few cases in patients with the acquired immunodeficiency syndrome (AIDS) ${ }^{3-8}$ Nevertheless, outside psychiatry, the syndrome probably remains underdiagnosed, as its manifestations may be also caused by other processes such as infections and neoplasms. Thus, a high index of suspicion is needed to not miss the diagnosis in medical patients. This is particularly important in patients infected by the human immunodeficiency virus (HIV), who commonly suffer infectious complications but also often receive psychoactive drugs. This article reviews the main features of NMS in AIDS patients. A typical case history is given in box 1 .

\section{Epidemiology}

Agitation and other psychotic symptoms are common in HIV-infected patients and they are frequently treated with neuroleptics. In fact, apathy, social withdrawal and personality changes have been reported to occur even before the development of the typical manifestations of HIV infection. ${ }^{9}$ In addition, neuroleptic-related drugs are commonly used to control other symptoms, such as nausea and vomiting.

The first case describing the association of NMS with AIDS was reported in 1986 by Bernstein and Scherokman, in a patient with disseminated histoplasmosis. $^{3} \mathrm{Up}$ to date, only eight cases of this association have been reported (see table). However, the actual incidence of NMS in the setting of AIDS is unknown. It is likely that many cases still go unrecognised because of the limited knowledge of this syndrome by clinicians. In a recent study, the majority of healthcare professionals tested did not know enough about NMS to aid early detection and to prevent its high mortality. ${ }^{10}$

NMS can occur in all age groups, but is more often found in young and middle-aged adults. ${ }^{11}$ Among AIDS patients, NMS also predominantly affects young men (table). The average age was 34.1 years (range 21 to 49). The drugs most frequently implicated in AIDS-related NMS have been haloperidol, trimethobenzamide and prochlorperazine.

\section{Pathogenesis and risk factors}

NMS is considered an idiosyncratic reaction to antipsychotic and related drugs. The prevailing theory relates NMS to a profound decrease of dopaminergic function in the central nervous system. The loss of dopaminergic activity in the nigrostriatal system would cause rigidity and tremor. The sustained muscle activity would result in increased production of heat, which, together with the alteration of hypothalamic and other autonomic centres, may cause fever and rhabdomyolysis. ${ }^{11,12}$

The incidence of extrapyramidal side-effects due to neuroleptics and related drugs, including metoclopramide, is increased in AIDS patients. ${ }^{13,14}$ The cause of this higher frequency of adverse effects remains speculative, but is probably related to the presence of predisposing structural brain abnormalities, due to opportunistic infections or to HIV infection itself. In this sense, the report of Reyes et al, showing that nigral degeneration is common in AIDS patients is interesting, ${ }^{15}$ as this would certainly predispose to extrapyramidal effects. Although the prevailing theory relates NMS to a profound decrease of dopaminergic function in the central nervous system, drugs triggering NMS 


\begin{tabular}{|c|}
\hline Case report \\
\hline $\begin{array}{l}\text { A } 32 \text {-year-old HIV seropositive white } \\
\text { man with a previous diagnosis of AIDS } \\
\text { (stage C3 according to CDC criteria), } \\
\text { presented with pneumonia. He was an } \\
\text { intravenous drug abuser with eight } \\
\text { months of abstinence, and there was } \\
\text { no history of dementia or psychiatric } \\
\text { disorders. } \\
\text { The patient was febrile and } \\
\text { inspiratory crackles were heard over } \\
\text { the lowest third of right lung. The } \\
\text { remainder of the examination was } \\
\text { normal. Chest X-ray showed an } \\
\text { alveolar infiltrate in the right lower } \\
\text { lobe. Intravenous erythromycin and } \\
\text { cefotaxime were given. Blood cultures } \\
\text { yielded Streptococcus pneumoniae and } \\
\text { erythromycin was withdraw. By the } \\
\text { fifth day he became afebrile. } \\
\text { On hospital day } 11 \text {, the patient } \\
\text { developed agitation and paranoid } \\
\text { ideations. He was started on } \\
\text { haloperidol (6 mg/day per os), and oral } \\
\text { biperiden. Three days later, the patient } \\
\text { became febrile (39.5 }{ }^{\circ} \text { ), with } \\
\text { tachycardia, tachypnoea, profuse } \\
\text { diaphoresis, cogwheel rigidity of all } \\
\text { extremities, akinesia and fluctuating } \\
\text { consciousness with mutism. } \\
\text { Leukocytosis with a left shift was } \\
\text { present, and creatine kinase level was } \\
2365 \text { U/l. Exhaustive microbiological } \\
\text { studies were negative. Chest X-ray } \\
\text { showed no infiltrates. A cranial CT } \\
\text { scan was normal, and CSF } \\
\text { examination and cultures failed to } \\
\text { reveal any evidence of infection. } \\
\text { Haloperidol was discontinued. Within } \\
48 \text { h his temperature, creatine kinase } \\
\text { and neurological status were normal. } \\
\text { However, psychotic symptoms } \\
\text { recurred and oral loxapine (100 mg/ } \\
\text { day) was given. One day later fever } \\
\text { (39 }{ }^{\circ} \text { C), stupor, and extrapyramidal } \\
\text { signs reappeared. As before, no } \\
\text { evidence for infection was found. By } \\
\text { the second day after loxapine } \\
\text { withdrawal his body temperature and } \\
\text { neurologic status were again normal. }\end{array}$ \\
\hline
\end{tabular}

Box 1

\section{Risk-factors for NMS frequently present in AIDS patients}

- high doses (ie, more than $15 \mathrm{mg} /$ day) of haloperidol

- rapid increase in the dose of a neuroleptic

- neuroleptics in depot formulations

- a preceding attack of NMS

- malnutrition

- dehydration

- exhaustion

- organic cerebral disease

- alcoholism

- psychomotor excitement

- affective disorder interact not only with dopaminergic transmission, but also with several other cell systems. It remains unclear why only some patients develop the syndrome. Dehydration and acute psychotic agitation are common features in AIDS patients. The former is associated with an increase of extracellular sodium, and the second with an decrease of calcium in the cerebrospinal fluid. These mechanisms may lead to a decrease of intraneuronal calcium, which could facilitate an increase of adenylate cyclase activity, and a subsequent disturbance of thermoregulation, thus predisposing to NMS. ${ }^{16}$

Whatever pathophysiological mechanisms may be involved, clinical studies have suggested that some concomitant factors increase the risk of developing NMS. ${ }^{17}$ Many of these factors often occur in HIV-infected patients (box 2), several of which were present in the reported patients with AIDS and NMS, including malnutrition, concomitant brain disease, increasing dose of or treatment with a new neuroleptic, schizo-affective disorder, and the antecedent of a preceding attack of NMS (table, cases 1, 2 and 8).

\section{Clinical features}

\section{SYMPTOMS AND SIGNS}

The characteristic tetrad of NMS includes hyperthermia, extrapyramidal rigidity of skeletal muscles, fluctuating consciousness, and instability of the autonomic nervous system. ${ }^{11,12,18}$ Symptoms and signs of NMS in AIDS patients are summarised in the table. The clinical features of patients with AIDS do not seem to differ from those observed in other patients with NMS. Hyperthermia was constant in all patients; in about half body temperature was higher than $40^{\circ} \mathrm{C}$. Extrapyramidal-type hypertonia, often along with bradykinesia or akinesia, was also present in the vast majority of patients. Rigidity of the thoraco-abdominal muscles may result in hypoventilation and respiratory failure (cases 5 and 9). Tremor was present in two patients.

The development of the complete NMS may be preceded by insidious changes in mental status or autonomic functions. All AIDS-patients with NMS displayed alteration of consciousness, psychomotor excitement or aggressive behaviour before the onset of the full syndrome. In AIDS-patients the most common signs of autonomic dysfunction were tachycardia, tachypnoea and diaphoresis. Mild dysphagia was present in one case.

Most cases developed in the first week after initiating the offending drug, but in two patients NMS was diagnosed later. Symptoms usually developed over a period of 24 to 72 hours, and the mean recovery time was five to 10 days.

\section{LABORATORY FINDINGS}

Leucocytosis with or without a left shift is very common. ${ }^{11,12,18}$ However, the number of leukocytes was not always reported in the published cases of NMS and AIDS. Therefore, it is unclear how frequent leucocytosis is in this population who often have previous leucopenia. Most patients with NMS also show an elevated serum creatine kinase level, probably due to myonecrosis during sustained muscle contraction. It may evolve into frank rhabdomyolysis and renal failure, the most common serious complication of NMS. Most patients with AIDS and NMS showed elevated serum creatine kinase levels, but acute renal failure only occurred in one case. ${ }^{5}$ However, it must be stressed that the diagnosis should not over-rely on increased creatine kinase levels, as this is a common and nonspecific finding in patients taking neuroleptics who become infected. ${ }^{19}$

Electroencephalograms were normal or showed nonspecific signs of encephalopathy. Cerebrospinal fluid (CSF) was normal or presented a nonspecific slight increase in proteins. Cranial computed tomography (CT) showed no abnormalities. Albeit non-diagnostic, those tests served to rule out opportunistic infections before making the diagnosis of NMS in the setting of AIDS.

\section{Diagnosis}

There is no universal agreement about the diagnostic criteria for NMS, although several sets of criteria have been proposed. Among the more widely used are those published by Levenson in 1985 (box 3). ${ }^{18}$ All reported cases of AIDS-related NMS fulfilled these criteria. Other groups have proposed somewhat different criteria. ${ }^{11,20,21}$ The Diagnostic and statistical manual of mental disorders-fourth edition (DSM-IV) has recently incorporated research criteria for NMS (box 4). ${ }^{22}$

Given the lack of consensus about diagnostic criteria, it is not surprising that the reported frequency of NMS had varied from 0.07 to $12.2 \% .^{11,12,17}$ One 
Table Summary of case histories of AIDS patients with NMS

\begin{tabular}{|c|c|c|c|c|c|c|c|c|}
\hline Ref & Age & Sex & Drugs & $\begin{array}{l}\text { Total } \\
\text { dose } \\
(m g)\end{array}$ & $\begin{array}{l}\text { Days } \\
\text { until } \\
\text { NMS }\end{array}$ & Presentation & $\begin{array}{l}C K \max . \\
(U / l)\end{array}$ & Treatment \\
\hline 3 & 26 & $\mathbf{F}$ & $\begin{array}{l}\text { prochlorperazine } \\
\text { trimethobenzamide } \\
\text { droperidol } \\
\text { haloperidol }\end{array}$ & $\begin{array}{l}\text { NR } \\
\text { NR } \\
\text { NR } \\
\text { NR }\end{array}$ & $\begin{array}{l}5 \\
5 \\
5 \\
\text { NR }\end{array}$ & $\begin{array}{l}\text { fever/mutism/akinesia } \\
\text { tremor/rigidity }\end{array}$ & 2515 & withdrawal \\
\hline 4 & 49 & $\mathbf{M}$ & $\begin{array}{l}\text { haloperidol } \\
\text { fluphenazine } \\
\text { benztropine } \\
\text { thiothixene }\end{array}$ & $\begin{array}{l}21.5 \\
60 \\
60 \\
16\end{array}$ & $\begin{array}{l}7 \\
15 \\
15 \\
4\end{array}$ & $\begin{array}{l}\text { fever/mutism/akinesia } \\
\text { rigidity/lethargy } \\
\text { tachycardia }\end{array}$ & NR & $\begin{array}{l}\text { withdrawal, } \\
\text { amantadine }\end{array}$ \\
\hline \multirow[t]{2}{*}{4} & 33 & $M$ & chlorpromazine & 900 & 5 & fever/rigidity & 3770 & $\begin{array}{l}\text { withdrawal, } \\
\text { bromocriptine }\end{array}$ \\
\hline & & & haloperidol & 2 & 1.5 & tachycardia/diaphoresis & & \\
\hline 4 & 31 & $\mathbf{M}$ & haloperidol & 21 & 3 & $\begin{array}{l}\text { fever/rigidity/tremor/ } \\
\text { confusion/tachycardia/ } \\
\text { tachypnoea }\end{array}$ & 1162 & withdrawal \\
\hline 5 & 21 & $\mathbf{M}$ & prochlorperazine & 75 & 1 & $\begin{array}{l}\text { fever/rigidity/seizures/ } \\
\text { stupor/tachycardia/ } \\
\text { tachypnoea/incontinence }\end{array}$ & NR & withdrawal \\
\hline 6 & 48 & $\mathbf{M}$ & $\begin{array}{l}\text { trimethobenzamide } \\
\text { thiethylperazine }\end{array}$ & $\begin{array}{l}1250 \\
\text { NR }\end{array}$ & $\begin{array}{l}5 \\
1\end{array}$ & $\begin{array}{l}\text { fever/rigidity/akinesia } \\
\text { mutism/tachycardia/ } \\
\text { tachypnoea/diaphoresis }\end{array}$ & 71437 & withdrawal \\
\hline 7 & 33 & $\mathbf{M}$ & $\begin{array}{l}\text { haloperidol } \\
\text { benztropine }\end{array}$ & $\begin{array}{l}11 \\
\mathrm{NR}\end{array}$ & 15 & fever/rigidity/mutism & 6606 & $\begin{array}{l}\text { withdrawal, } \\
\text { dantrolene }\end{array}$ \\
\hline 8 & 27 & $\mathbf{M}$ & $\begin{array}{l}\text { clotiapine } \\
\text { alizapride }\end{array}$ & $\begin{array}{l}600 \\
450\end{array}$ & $\begin{array}{l}30 \\
3\end{array}$ & $\begin{array}{l}\text { fever/rigidity/bradykinesia } \\
\text { drowsiness/difficulty in } \\
\text { swallowing }\end{array}$ & 690 & $\begin{array}{l}\text { withdrawal, } \\
\text { levodopa, } \\
\text { dantrolene, } \\
\text { clonazepam }\end{array}$ \\
\hline $\begin{array}{l}\text { Present } \\
\text { case }\end{array}$ & 32 & $\mathbf{M}$ & $\begin{array}{l}\text { haloperidol } \\
\text { loxapine }\end{array}$ & $\begin{array}{l}18 \\
100\end{array}$ & $\begin{array}{l}3 \\
1\end{array}$ & $\begin{array}{l}\text { fever/rigidity/akinesia } \\
\text { mutism/tachycardia/ } \\
\text { tachypnoea/diaphoresis }\end{array}$ & 2365 & withdrawal \\
\hline
\end{tabular}

$\mathrm{CK}=$ creatine kinase; $\mathrm{NR}=$ not reported; $\mathrm{PML}=$ progressive multifocal leukoencephalopathy; $\mathrm{PCP}=$ Pneumocystis carinii pneumonia

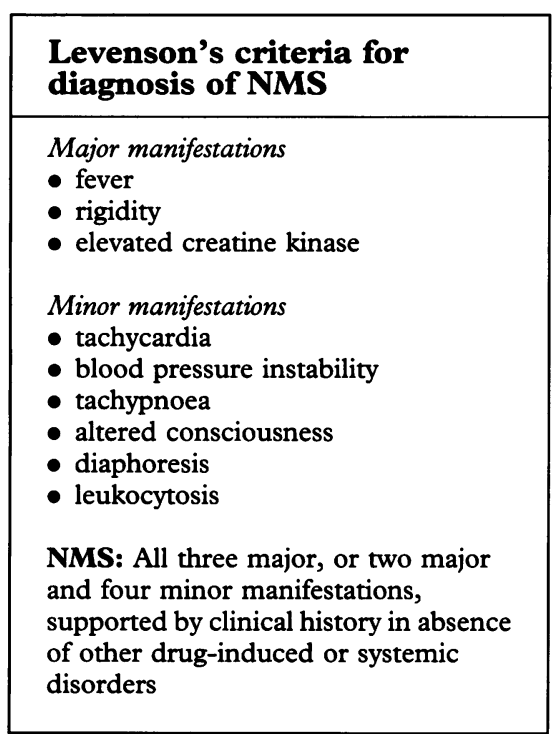

Box 3 particular point of debate is the so-called 'spectrum concept'. Some authors consider that NMS is the extreme end of the spectrum of neuroleptic-related neurotoxicity. The much more common mild neuroleptic-induced parkinsonism would be at the other end. Cases without fever, marked rigidity or altered consciousness, which some authors have called atypical NMS or 'forms frustes' of NMS, would be between those extremes. ${ }^{23}$ However, others consider NMS to be a distinct entity and regard the spectrum concept as a confusing contention that could cause mismanagement of extrapyramidal reactions to neuroleptics. ${ }^{20}$

\section{DIFFERENTIAL DIAGNOSIS}

Many disorders and toxic reactions can mimic the clinical manifestations of NMS (box 5).

\section{Lethal catatonia}

Lethal catatonia, a severe form of psychosis, is fortunately very rare nowadays. Patients with this disorder may present fever, rigidity, diaphoresis and decreased alertness. Therefore, when it occurs in patients on neuroleptics it may be indistinguishable from NMS. Stopping neuroleptics may help in the differential diagnosis. ${ }^{12,16,24}$

\section{Serotonin syndrome}

The so-called 'serotonin syndrome' is an adverse drug reaction that typically develops within hours (less frequently within days) of the addition of a serotonin agonist to a patient already taking some drug able to potentiate serotonin effects. Drugs commonly implicated include tryptophan, opioids (meperidine, dextromethorphan), different antidepressants (particularly the selective inhibitors of serotonin re-uptake and monoamine oxidase inhibitors), and the illicit drug methylenedioxymethamphetamine (MDMA or 'ecstasy'). Ecstasy can induce both hyperthermia and the serotonin syndrome, probably by toxic damage to serotonin nerve terminals. Clinical manifestations are very similar to NMS. Nevertheless, patients with the serotonin syndrome have a tendency for smaller increases in temperature, creatine kinase and leucocyte count, and a higher frequency of myoclonus. Those features, along the start of the 


\begin{tabular}{|l|}
\hline DSM-IV diagnostic criteria \\
for NMS \\
\hline - hyperthermia and \\
- muscle rigidity and two or more of: \\
- diaphoresis \\
- dysphagia \\
- tremor \\
- ancontinence \\
- tachycardia \\
- blood pressure changes \\
- leukocytosis \\
- raised creatine kinase \\
\hline
\end{tabular}

Box 4

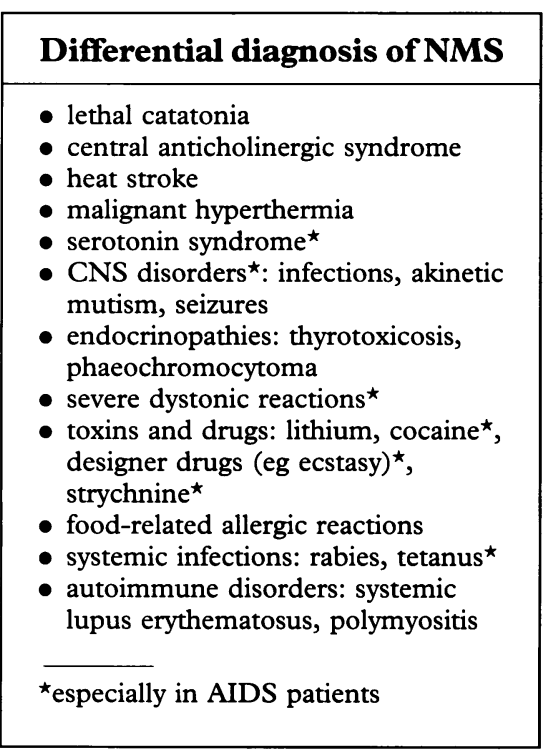

Box 5 manifestations within hours of drug ingestion, usually permit the correct diagnosis to be established. ${ }^{25-27}$ Given the widespread use of fluoxetine, and other selective serotonin re-uptake inhibitors to control depression in AIDS patients, serotonin syndrome cannot be overlooked in the differential diagnosis of NMS in these patients.

\section{Malignant hypothermia}

This entity may also be clinically similar to NMS. The history of recent exposure to inhalational anaesthetics or depolarising agents usually allow the correct diagnosis to be made. It has also been suggested that the response to curare-like relaxants may help in the differential diagnosis. ${ }^{11,12}$

\section{Heat-stroke}

Heat-stroke occurring in patients on neuroleptics may sometimes be confused with the NMS. Indeed, neuroleptics, and other drugs with an anticholinergic effect, seem to increase the risk of heat-stroke in the presence of high ambient temperature. However, unlike NMS and exertional heat-stroke, classic heatstroke is characterised by anhidrosis. Moreover, although heat-stroke may be complicated with rhabdomyolysis and high creatine kinase levels, rigidity is unusual. ${ }^{11,12}$

\section{Central anticholinergic syndrome}

Anticholinergic intoxication usually present with fever, dry skin and confusion. It may be differentiated from NMS by the presence of peripheral signs of atropine poisoning (dry mouth, mydriasis, bowel paresis, urine retention) and the absence of rigidity. ${ }^{11,12}$

\section{Drugs and toxins}

Many other drugs and toxins may occasionally cause adverse reactions with some similarities to NMS. ${ }^{28}$ Lithium, strychnine poisoning, and toxic effects of cocaine, can mimic the clinical features of NMS and should be considered in the diagnosis of AIDS-related NMS, due to the widespread use of drugs by the HIV-infected patients. Hyperthermia, movement disorders and even rhabdomyolysis may complicate the illicit use of cocaine or its alkaloid form 'crack'. Nevertheless, AIDS patients with a history of cocaine abuse may be more at risk of NMS when treated with neuroleptics. The reason for this could be the blockade of D2 receptors by neuroleptic agents and the depletion of dopamine and dopamine receptors induced by cocaine. ${ }^{29}$ Thus, a detailed history of drug ingestion is critical for the correct diagnosis.

\section{Infectious diseases}

The first differential diagnosis to be entertained in patients suspected of having NMS is infection. ${ }^{11,12,18}$ This is particularly important in AIDS patients, who not only are more vulnerable to infections, but also frequently have atypical manifestations. Specifically, brain imaging (CT, nuclear magnetic resonance) and CSF analysis must be considered to exclude intracranial infection. The spectrum of central nervous system diseases in HIV-infected patients includes meningitis, meningoencephalitis, progressive multifocal leukoencephalopathy, focal lesions and global encephalopathy (reviewed in ref 30). In particular, Toxoplasma gondii encephalitis may present with hyperthermia, fluctuating consciousness and mild basal ganglia impairment in absence of other focal neurological signs or the characteristic CT findings. ${ }^{31}$ Imaging studies also help to exclude other structural lesions, particularly those that can produce akinetic mutism and cause confusion with NMS. Diagnostic schemes, such as Levenson's criteria (box 3), consider NMS as a diagnosis to be made after exclusion of other systemic processes. However, although an infection must certainly be excluded in any patient presenting with fever, it should be realised that infection and NMS are not mutually exclusive, specially in the setting of AIDS. Thus, in an infected patient taking neuroleptics or other drugs capable of causing NMS, the clinician should consider critically whether the infectious process itself explains all the clinical manifestations. In this scenario, the presence of muscle rigidity would be particularly suspicious of a drug reaction and prompt the discontinuation of the potentially offending drug.

\section{Prognosis}

The mortality of NMS ranges from 10 to $30 \%$ in most studies. ${ }^{11,12,15,16}$ In AIDS patients mortality was $33 \%$. Causes of death were respiratory insufficiency (case 5), acute renal failure and rhabdomyolysis (case 6), and sepsis (case 7). A 


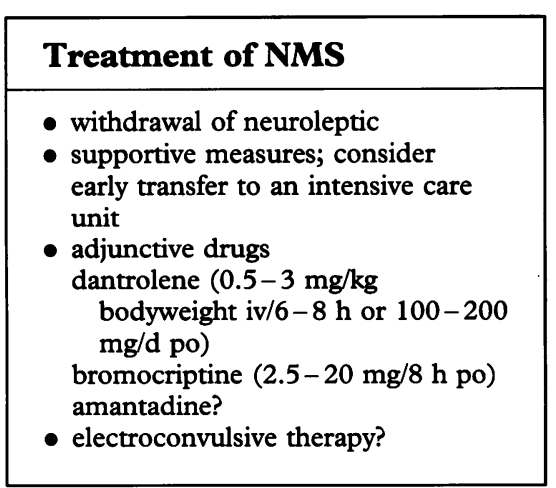

Box 6

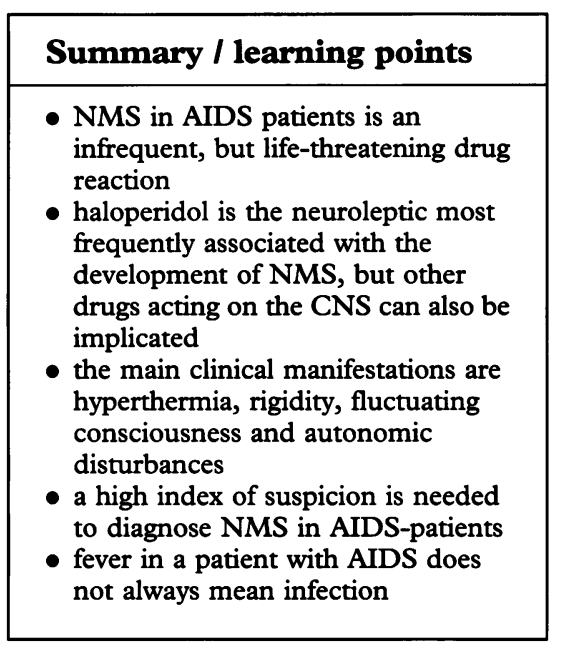

Box 7

Figure Suggested approach to AIDS patients with drug-induced extrapyramidal manifestations greater awareness of the syndrome, with earlier recognition and better supportive measures, may contribute to a decrease of this high mortality.

\section{Treatment}

The basis of treatment of NMS is the withdrawal of implicated drugs and institution of supportive measures. Attention should be given to the maintenance of adequate hydration with fluid and electrolyte replacement. Many uncontrolled studies suggest that bromocriptine and dantrolene are beneficial in NMS. ${ }^{11,12,16,18}$ Patients with NMS and AIDS have been treated in various ways, being impossible to draw conclusions about drug efficacy. Nevertheless, two of five patients not receiving dantrolene or dopamine agonists died, whereas only one of the four patients treated with those drugs had an unfavourable outcome. Thus, dantrolene and bromocriptine may also have a beneficial effect in the management of AIDS-related NMS. Benzodiazepines were used to control anxiety and muscular rigidity in two patients. Transfer to an intensive care unit was only reported in one patient (case 5). However, it must be certainly considered in patients with cardiovascular instability or respiratory difficulties. Electroconvulsive therapy has been safely administered to patients with AIDS and major depression, ${ }^{32}$ and in some immunocompetent patients with NMS, ${ }^{11}$ but not in AIDS-related NMS.

As mentioned above, in patients on neuroleptics who develop muscle rigidity, it may sometimes be difficult to ascertain whether this is a 'common' extrapyramidal reaction or represents the initial phase of a full-blown episode

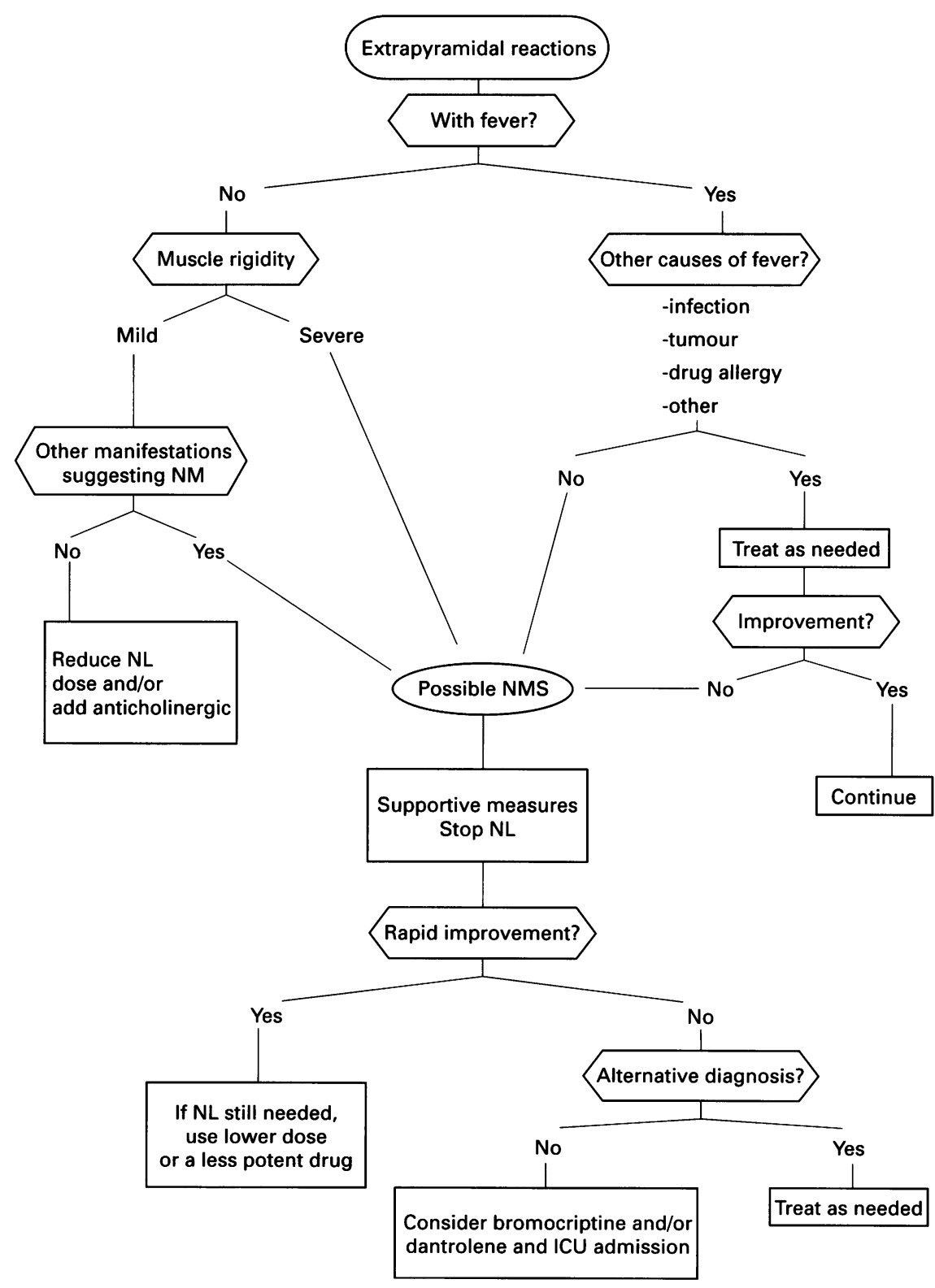


1 Smego Jr RA, Durack DT. The neuroleptic malignant syndrome. Arch Intern Med 1982; 142. malignant $1183-5$.

2 Delay J, Deniker P. Drug-induced extrapyramidal syndromes. In: Vinken PJ, Bruyn GW, midal syndromes. In: Vinken PJ, Bruyn GW, eds. Handbook of clinical neurology, Vol 6. Diseases
of the basal ganglia. Amsterdam: North-Holland of the basal ganglia. Amsterdam:

Publishing, 1968; pp 248-66.
3 Bernstein WB, Scherokman B. Neuroleptic malignant syndrome in a patient with acquired immunodeficiency syndrome. Acta Neurol Scand 1986; 73: 636-7.

4 Breitbart W, Marotta RF, Call P. AIDS and neuroleptic malignant syndrome (letter). Lancet 1988; 31: $1488-9$.

5 Manser TJ, Warner JF. Neuroleptic malignant syndrome associated with prochlorperazine. syndrome associated with
South Med f 1990; 83: $73-4$.

6 Edelstein HE, Chirurgi VA, Gloudeman MW, Beckley DJ, McCabe RE. Adverse reactions to phenothiazine antiemetics in AIDS. DICP 1991; 25: 1007

7 Burch EA Jr, Montoya J. Neuroleptic malignant syndrome in an AIDS patient (letter). $\mathcal{F}$ Clin Psychopharmacol 1989; 9: 228-9.

8 Gabellini AS, Pezzoli A, De Massis P, Casadei G, Grillo A, Sacquegna T. Neuroleptic malignant syndrome in an AIDS patient: clinical and pathological findings. Ital $\mathcal{f}$ Neurol Sci 1994; 15 : pathologice.

9 Lazarus A. EPS, NMS, and AIDS (letter). Biol Psychiatry 1990; 28: $551-2$.

10 De la Cour J. Neuroleptic malignant syndrome: do we know enough?. $\mathcal{F}$ Adv Nurs 1995; 21 $897-904$

11 Caroff SN, Mann SC. Neuroleptic malignan syndrome. Med Clin North Am 1993; 77: 185 202. of NMS. Yet the distinction has important therapeutic importance. In the former case, anticholinergics could ameliorate the symptoms, whereas in NMS they may worsen hyperpyrexia. Thus, in doubtful cases, neuroleptics must be stopped (figure). Although still unproved, it is expected that stopping neuroleptics at early stages of NMS may prevent the development of the fullblown syndrome or ameliorate its severity.

About one third of patients who recover from NMS experience a recurrence when treated again with neuroleptics. If these drugs need to be given, delaying therapy for two or more weeks after complete recovery, use of low-potency drugs, and correction of other risk factors may help to decrease recurrence rate. ${ }^{11,12}$

12 Guzé BH, Baxter Jr LR. Neuroleptic malignant syndrome. $N$ Engl f Med 1985; 313: 163-6.

13 Perry SW. Organic mental disorders caused by HIV: update on early diagnosis and treatment. HV: update on early diagnosis and

14 Nath A, Jankovic J, Pettigrew C. Movement disorders and AIDS. Neurology 1987; 37: $37-$ 41 .

15 Reyes MG, Feraldi F, Senseng CS, Fariello R Nigral degeneration in acquired immunodeficiency syndrome (AIDS) (abstract). Neurology 1989; 39 (suppl 1): 427

16 Martínez E, Domingo P, Lloret J. Síndrome neuroléptico maligno. Med Clin (Barcelona) 1994; 102: $181-8$.

17 Naganuma H, Fujii I. Incidence and risk factors in neuroleptic malignant syndrome. Acta Psyin neuroleptic malignant synd

18 Levenson $\mathrm{L}$. Neuroleptic malignant syndrome. Levenson JL. Neuroleptic malignant
Am $\mathcal{F}$ Psychiatry $1985 ; 142: 1137-45$.

19 Buckley PF, Hutchinson M. Neuroleptic malignant syndrome. $f$ Neurol Neurosurg Psychiatry 1995; 58: $271-3$.

20 Jee A, Sing S, Singh G, Ong S. Spectrum concept of neuroleptic malignant syndrome. $B r f$ Psychiatry 1988; 153: $107-11$.

21 Pope HG Jr, Keck PE Jr, McElroy SL. Frequency and presentation of neuroleptic malignant syndrome in a large psychiatric hospital. Am $\mathcal{F}$ Psychiatry 1986; 143: 1227-33.

22 Diagnostic and statistical manual for mental disorders. Fourth edition (DSM-IV). Washington orders. Fourth edition (DSM-IV). Washington DC:

23 Shalev A, Munitz H. The neuroleptic malignant syndrome:agent and host interaction. Acta Psychiatr Scand 1986; 73: 337-47.
24 Goeke JE, Hagan DS, Goelzer SL, Coursin DB. Lethal catatonia complicated by the development of neuroleptic malignant syndrome in a middle-aged female. Crit Care Med 1991; 19: middle- $1445-8$.

25 Bodner RA, Lynch T, Lewis L, Kahn D Serotonin syndrome. Neurology 1995; 45: 219 24.

26 Brown TM, Skop BP, Mareth TR. Pathophysiology and management of the serotonin syndrome. Ann Pharmacother 1996; 30: 527-33.

27 Ames D, Wirshing WC. Ectasy, the serotonin syndrome, and neuroleptic malionant syndrome-a possible link? (letter) $f A M A$ 1993; 269: 869 .

28 Nimmo SM, Kennedy BW, Tullet WM, Blyth AS, Dougall JR. Drug-induced hyperthermia. An, Dougall JR. Drug-induced

29 Daras M, Kakkouras L, Tuchman AJ, Koppel BS. Rhabdomyolysis and hyperthermia after cocaine abuse: a variant of the neuroleptic malignant syndrome? Acta Neurol Scand 1995; 92: $161-5$.

30 Berger JR, Levy RM. The neurological complications of acquired immunodeficiency virus

31 Carrazan EJ Clin North Am 1993; 779 Parkinsonian symossitch $\mathrm{E}$ Jr, Sam and cerebral toxoplasmosis. $\mathcal{f}$ Neurol Neurosurg Psychiatry 1989; 52: 1445-7.

32 Davis JM, Janicak PG, Sakkas P, Gilmor C, Wang $Z$. Electroconvulsive therapy in the treatWang $Z$. Electroconvulsive therapy in the treat-
ment of the neuroleptic malignant syndrome. ment of the neuroleptic malig
Convuls Ther 1991; 7: 111-20. 